\title{
FEATURE
}

\section{Big interdisciplinarity to address climate change and agriculture: Lessons from three USDA Coordinated Agricultural Projects}

\author{
Sanford D. Eigenbrode, Lois Wright Morton, and Timothy A. Martin
}

\section{THE NEED: ADDRESSING CLIMATE CHANGE IMPLICATIONS FOR UNITED STATES AGRICULTURAL SYSTEMS}

Climate change affects entire production systems from agronomics to economics, farm to region, cropping systems to nutrient management, and plant protection to sociology (Walthall et al. 2012). All of these components interact such that none can be understood adequately in isolation. The call for more integrated, long-term, regional agricultural projects to address processes and challenges like climate change has been well articulated (Robertson et al. 2008). This call is consistent with a general recognition of the need for broadly collaborative science to address complex problems (National Academy of Sciences 2004; Palmer 2012; National Research Council 2014). For US agriculture and forestry, the partnership between federal scientists, land grant scientists, extension service, and producers has helped make US food and fiber production systems a model for the world. Addressing the complex, system-level challenges in a newly integrated and coordinated fashion can help us continue to excel in managing our uniquely successful agricultural enterprise, and to provide global leadership in this area. Mechanisms for realizing this integration are coalescing as evidenced by recent establishment of the USDA's Long Term Agricultural Research Site Network (USDA ARS 2014) and the evolving USDA Climate Hubs (USDA 2014). However, how these activities will contribute to the overall vision of integrated climate and agriculture science that is responsive to stakeholder needs is still uncertain.

Sanford D. Eigenbrode is a professor of entomology and director of Regional Approaches to Climate Change for Pacific Northwest Agriculture, University of Idaho, Moscow, Idaho. Lois Wright Morton is a professor of sociology and director of Climate and Corn-based Cropping Systems Coordinated Agricultural Project, College of Agriculture and Life Sciences, lowa State University, Ames, lowa. Timothy A. Martin is a professor and director of Pine Integrated Network: Education, Mitigation and Adaptation Project, School of Forest Resources and Conservation, University of Florida Gainesville, Florida.
One of the most ambitious initiatives to understand and improve the resilience of agricultural systems to climate change while mitigating greenhouse gas emissions and increasing carbon (C) sequestration is the USDA Agriculture and Food Research Initiative Coordinated Agricultural Projects (CAPs) within the agency's Climate Variability and Change challenge area. National Institute of Food and Agriculture (NIFA) CAPs bring together teams of researchers to support discovery and applications and promote communication leading to innovative, science-based solutions to critical and emerging national priorities. Three US $\$ 20$ million Climate CAPs were selected for funding under this program in 2011. These projects involve multiple investigators working across many disciplines to reduce greenhouse gas emissions, increase $\mathrm{C}$ sequestration, and help key agriculture and forestry systems become climate smart. The CAPs all have efforts in research, extension, and education involving multiple institutions. Thus, our goals are not only to influence current and future production practices but to increase the capacity for institutional research, education, and extension to address climate impacts on agriculture (NIFA RFA 2010).

\section{BIG INTERDISCIPLINARITY: \\ CLIMATE CHANGE COORDINATED AGRICULTURAL PROJECTS}

NIFA's Climate CAPs are "big science"much smaller than well-known big science efforts such as space exploration and particle physics (Weinberg 1961; Galison 1994), but large compared to typical USDA-funded projects. Furthermore, their transdisciplinary approach requires what may be termed "big interdisciplinarity," which presents novel opportunities and challenges. As the directors of these projects, the authors of this paper have collaborated in their execution. Here we review the status of these projects and how we have addressed the challenges and opportunities they present, which we hope will be relevant for similar large projects designed to address long-term challenges facing agriculture in the future.

\section{OVERVIEWS OF THE \\ CLIMATE COORDINATED \\ AGRICULTURAL PROJECTS}

Each of the climate CAPs addresses production systems spanning several states (figure 1). They are multi-institution, multi-investigator, transdisciplinary projects focused on climate change adaptation and mitigation in their specific production system and region. Each primarily emphasizes research, but also has significant commitment to extension, outreach, and education (table 1). Detailed descriptions are beyond the scope of this short article, but more information is available through their respective websites (www. pinemap.org/; www.reacchpna.org/; and www.sustainablecorn.org/). Table 2 contains some of the highlights of the outputs and outcomes of these three projects since they were launched in 2011.

\section{MEETING THE CHALLENGES OF BIG INTERDISCIPLINARITY WITHIN THE NATIONAL INSTITUTE OF FOOD AND AGRICULTURE CLIMATE COORDINATED AGRICULTURAL PROJECTS}

As directors and participants in our respective CAPs, our teams have encountered several unique challenges and opportunities inherent in big interdisciplinary projects. We review them here with an aim to help future largescale efforts designed to address challenges associated with complex issues facing agriculture and other large integrated systems.

Maintaining Project Cohesion and Shared Mission. Managers of large projects are challenged to ensure that participants are able to comprehend and contribute meaningfully to the overarching goals and understand how their work fits into the project as a whole. Our CAPs have approached this in different ways, but each has developed one or more overarching conceptual models that were generated and modified by participants. The Regional Approaches to Climate Change (REACCH) project, for example, has distilled the project logic model into a graphic representation, which was discussed and modified by PIs (principal investigators), graduate students, and postdocs during a half-day workshop. 


\section{Figure 1}

The geographic domains of the three USDA National Institute of Food and Agriculture Coordinated Agricultural Projects: USDA National Institute of Food and Agriculture award numbers 2011-68002-30190, 2011-68002-30191, and 2011-68002-30185.

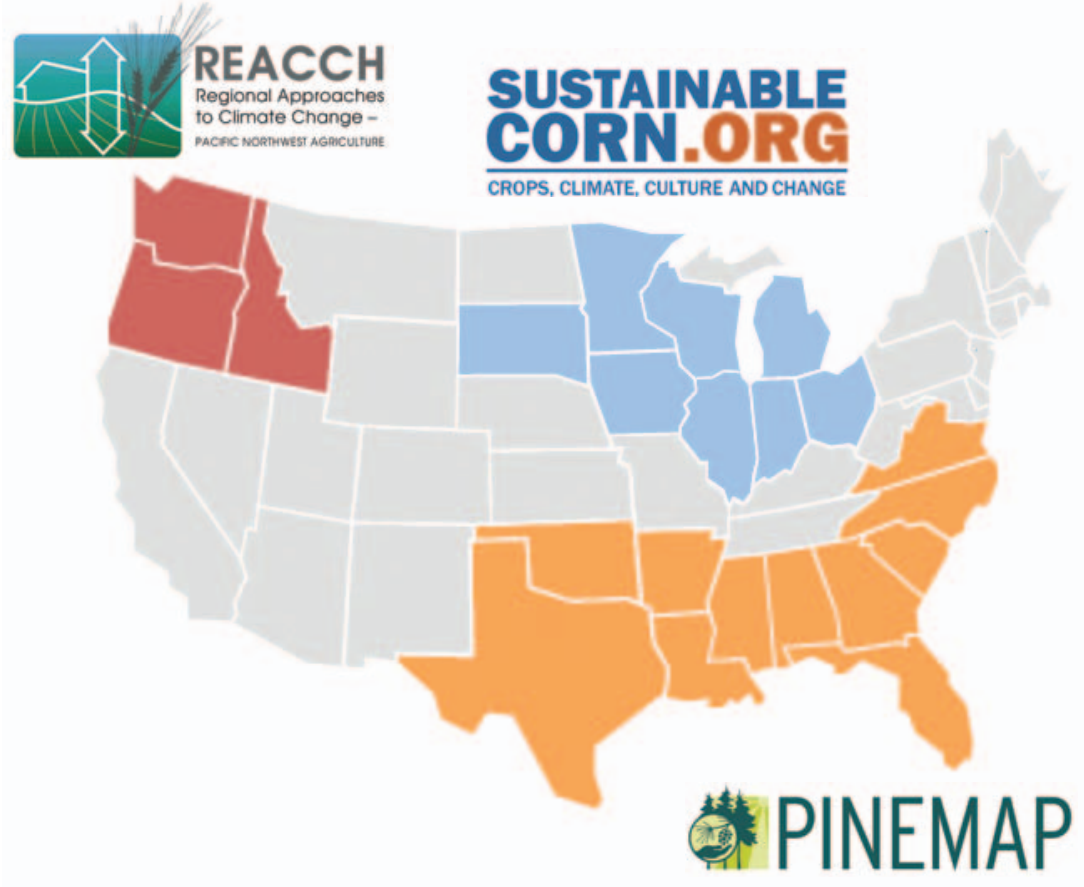

Participants locate their own work within this structure when presenting their work in a whole-project context. Early in their development, the Sustainable Corn CAP team reconceptualized their transdisciplinary goals by explicitly focusing on integration in small and large groupings, communication strategies, and the use of research output as inputs for extension, education, and interdisciplinary research. Two of the projects have employed Social Network Analysis (Kadushin 2012) to help visualize the collaborative environments they are creating. The Pine Integrated Network: Education, Mitigation and Adaptation Project (PINEMAP) generated a survey-based social network analysis of the project and encouraged participants to explore how their place in the network affected their contributions to interdisciplinary project goals and opportunities to strengthen the project by building new connections. Each year, the PINEMAP team revisits an updated network analysis and discusses how evolving project connections and structure can be best used to achieve project outcomes. REACCH conducted a similar analysis and has used analyses and visualizations of the network to build project awareness of key nodes, boundaries, and brokers.

Also essential for maintaining project cohesiveness are regular face-to-face meetings. Each CAP holds a two-day to two-and -a-half-day annual meeting that includes opportunities for the science to be shared among participants and with stakeholders through talks, posters, and workshops. Our annual meetings also include field days and a variety of other activities designed to cross inform participants, encourage collaboration, and promote engagement with stakeholders. We rely on internal expertise and outside professionals to facilitate parts of these meetings.

Bridging Cultural Divides. In one or more senses, large collaborations will typically involve participants from different cultures. These include the epistemic cultures underlying different disciplinary traditions (Klein 1996). Interdisciplinary collaborations confront not only the ubiquitous tension in science between corroborative vs. innovative incentive (Kuhn 1959), but also the tension

\section{Table 1}

National Institute of Food and Agriculture's Climate Coordinated Agricultural Projects (CAPs) in a nutshell.

\section{Project}

Climate and Corn-based

Cropping Systems

(Sustainable Corn CAP)

Pine Integrated Network: Education, Mitigation and Adaptation Project (PINEMAP)

\section{Regional Approaches to} Climate Change for Pacific Northwest Agriculture (REACCH-PNA)

\section{Description}

A partnership among 10 land grant universities and USDA Agricultural Research Service in Columbus, Ohio, this project has 42 principal investigators, 48 research/technical staff, 23 extension educators, 16 postdoctoral scientists, 72 graduate students, and 80 undergraduates. The Sustainable Corn team is measuring carbon, nitrogen, greenhouse gas emissions, and water flows associated with different corn-based cropping systems in the Upper Midwest where more than $70 \%$ of the US corn crop is grown; and is working closely with corn-soybean farmers to ensure productivity while protecting soil and water resources.

This project involves 57 principal investigators, 25 research and technical staff, 51 graduate students, and 7 postdoctoral scientists at 11 land grant institutions and the USDA Forest Service in the southeastern United States. PINEMAP focuses on the $>10$ million ha of planted pine forests managed by private landowners in the Atlantic and Gulf coastal states from Virginia to Texas, plus Arkansas and Oklahoma.

This project involves 3 land grant universities (Oregon State University, Washington State University, and the University of Idaho) and the USDA Agricultural Research Service. Currently there are 28 principal investigators, 15 support scientists, 11 postdoctoral scientists, 35 graduate students, and 12 to 15 undergraduate summer interns each year. Its focus is primarily on the $>3$ million ha in primarily rain-fed wheat production systems of northern Idaho, north central Oregon, and eastern Washington, which annually produce 3.5 million t of wheat conservatively exceeding US $\$ 500$ million annually and producing $13 \%$ of the nation's wheat supply. 


\section{Table 2}

Highlights of outputs and outcomes from three USDA National Institute of Food and Agriculture Climate Coordinated Agricultural Projects (Award Nos. 2011-68002-30190, 2011-68002-30191, and 2011-68002-30185) from their award dates in 2011 to July of 2014.

\section{Outputs}

Extension outreach

Scholarly publications and presentations

Production system baselines

Social and economic baseline assessments of production practices Climate impact projections on agriculture and forestry

Decision support systems

Lifecycle assessments (LCA)

University courses

Secondary education resources

Addressing agriculture and climate change

Long-term data management Students

Greater agricultural awareness of climate-related issues

Climate adaptation and mitigation
Examples

More than 1,000 presentations, news stories, fact sheets, webinars, workshops, and outreach efforts for agricultural and forestry professionals

270 scholarly publications, 21 thesis, dissertations, and other print publications; 822 scholarly presentations at professional meetings

Regional assessments of carbon, nitrogen and water across a range of climate, soils, and management regimes; nitrous oxide emissions from wheat and corn cropping systems; principal insect pests, weeds and diseases assessments

Regional surveys of extension professionals, forest managers, foresters, and corn producers about climate change, production practices, adaptation strategies, and enterprise budgets

Downscaled yield projections for wheat in the Pacific Northwest and corn in the Corn Belt; impacts of selected pests; regional fine scale plantation forest productivity and timber supply; Corn Belt farmers' adaptations and impacts on landscape and water quality

Southern pine decision support focused on capitalizing on opportunities and mitigating risk

Assessing carbon sequestration by production and use of wood products in southern pine plantations; LCA comparisons of current practices and experimental treatments (no-tillage, variable nitrogen rate, and cover-crop treatments) in corn-based production systems

Interdisciplinary graduate course, online geospatial data management and manipulation graduate course, annual seminar on climate change in relation to agriculture and forestry

Secondary curriculum modules for teachers and schools in all three project regions, 161 undergraduate fellow presentations to middle or high school students

Contributions to National Climate Assessment Report (Melillo et al. 2014); the USDA Climate Adaptation Report (Walthall et al. 2013); Science, Education and Outreach Roadmap for Natural Resources (Association of Public and Land-grant Universities 2014); and regional climate assessments (Dalton et al. 2013)

Systems to curate new and legacy datasets for scientists and stakeholders

158 graduate students, 34 postdocs, 125 undergraduate research interns trained and mentored

Tech transfer of climate and resilience research to managers of $>10$ million ha of southern pine plantations; managers of $>3$ million ha of Northwest wheat systems, and managers of 35.6 million ha of Midwest corn systems

$40 \%$ growth in two years of oilseed brassica and legumes use in wheat systems, fourfold increases in use of precision agriculture tools in wheat, 50\% acreage increases in soil and soil carbon conservation planting methods, increasing use of cover crops in corn systems, new tool to guide climate-based deployment of southern pine germplasm between ensuring disciplinary integrity and facilitating creativity at cross-disciplinary boundaries (Andersen 2013). Epistemic cultural differences, especially when unrecognized, can impede communication among collaborators. Each of our projects has encouraged discussion to reveal such differences. In all our projects, interdisciplinary working groups facilitate communication by focusing interactions on relatively discrete, outcome-focused activities. REACCH has undertaken workshops designed to reveal the philosophically rooted diversity among scientific disciplines (Eigenbrode et al. 2007; Looney et al. 2013).

Cultural differences also exist among institutions, with significant consequences for project cohesion (Cummings and Kiesler 2005). For example, in a survey of REACCH participants, responses indicated interinstitutional differences substantively affected perceived levels of collaboration (D. Meyer, unpublished). These institutional differences, which can range from the mundane, such as academic calendars or operational procedures, to the complex and subtle, including how interdisciplinary scholarship is valued and rewarded, together comprise "coordination costs" of collaboration (Cummings and Kiesler 2007), which can reduce productivity. Although we are unaware of formulae for successfully bridging institutions, knowledgeable liaisons for interfacing institutional bureaucracies and an appreciation by teams of the significance of interinstutional divides are requisite.

Bridging Geographic Divides. The cultural divide among institutions also implies geographic separation, which limits faceto-face interactions that are critical for the quality of collaborations (Maznevski and Chudoba 2000). Geographically distributed projects must employ various approaches to compensate for the lack of face-to-face opportunities. Our projects employ virtual collaborative tools, including Skype (www. skype.com), Gotomeeting (Citrix Online LLC), and Adobe Connect (success.adobe. com), as well as intranet platforms, such as Google Docs (https://docs.google.com) and Central Desktop (http://www.centraldesktop.com), to facilitate sharing of information and collaborations among participants. Team leaders within our projects use similar or identical platforms and tools for collaboration to improve continuity. The NIFA CAP projects employ a set of best practices for online communication and are working to find virtual alternatives to face-to-face interactions to promote cross-project collaborative creativity.

Supporting Architectures of Adaptive Integration. The large CAP projects are nec- 
essarily multiteam systems, with challenges like other large organizations with specialized subteams together working towards superordinate goals, i.e., those accepted by all the teams (Mathieu et al. 2001). This has engendered a still nascent theory for management of multiteam systems, which seeks to understand how teams work together and influence one another (Davison et al. 2012). NIFA CAPs offer insights into the dynamic structure and processes needed to successfully conduct the work of the project. Although collaborative research can be classified into disciplinary, multidisciplinary, interdisciplinary, transdisciplinary, and participatory engagement (Tress et al. 2007), large collaborative, multiteam projects, like CAPs, will have different types of integration proceeding simultaneously within predefined or ad hoc subteams. Large project organization and leadership can accommodate this diversity by acknowledging and facilitating an "Architecture of Adaptive Integration" (Morton et al. working paper) that incorporates awareness of team diversity in approaches, interteam interactions, and dynamics. This approach is consistent with the view that collaborations are complex systems in themselves (Vasileiadou 2012). As a part of this, in two of our CAPs we have used surveys to delineate project-wide social networks, which can improve collaborations (Haines et al. 2011). This exercise has revealed collaborative groupings and helped identify isolated participants as well as key brokers of projectwide cohesiveness.

Monitoring Project Productivity and Processes. Each of our projects has a NIFAmandated evaluation process to track progress towards milestones and deliverables and overall project goals. In addition, each of our CAPs has employed annual surveys to assess participant assessment with the quality and effectiveness of the collaboration and communication within it.

A challenge to evaluating large-scale efforts is to ensure metrics employed include not only standard outputs but those that can result uniquely from a large-scale project like CAPs. Some standard outputs, such as publications, may not scale linearly with the amount of funding (e.g., Fortin and Currie 2013). Our projects appear on target for a large number of refereed publications and other outputs (table 2), but a full assessment of this metric must await project comple- tions. In addition, our CAPs are focused on other kinds of outputs including "gray" publications and electronic media targeting stakeholders; changes in knowledge among stakeholders; changes in conditions, such as adoption of improved soil and nutrient management technology; and establishment of baselines, long-term experiments, or instrumentation with knowledge generation potential that will not be realized for many decades. Other outcomes evident to us, but difficult to measure, include cultural shifts toward improved capacity for integration and collaboration by PIs, postdocs, graduate and undergraduate students, and next generation farmers. Finally, our projects are charged to set regional trajectories to meet NIFA's targets for mitigation of greenhouse gas emissions and adaptation to climate change by 2030. CAP assessments are in place to gauge progress toward these targets, although final assessment must await measurements that can be made closer to that target date.

Educating Graduate and Undergraduate Students for Interdisciplinary Careers. Our projects include approaches to train graduate and undergraduate students to enhance their capacity to work within large projects that address complex problems (National Academy of Sciences 2004; Pfirman and Martin 2010; Derrick et al. 2012). All three CAPs have online distance education courses accessible by students across the project. For example, most PINEMAP graduate students are enrolled in a synchronous/asynchronous distance education course designed and offered by project PIs. The course had the broad goals of engaging graduate students in exploring climate change mitigation and adaptation issues in southern pine forests and building capacity for integration among research disciplines and between research and education/extension, and it was uniformly praised by participating students as an important experience for integrating with such a large project (Monroe et al. in press) Sustainable Corn graduate students have developed a roadmap for becoming a transdisciplinary scientist (Basche et al. 2014).This road map encourages professional, scientific, and outreach activities that bridge disciplines and build collaborative relationships. Graduate students in REACCH participate in workshops during annual retreats that include training in interdisciplinary com- munication skills using workshops patterned after Eigenbrode et al. (2007) and modified by students to meet specific needs in our project. Our projects have also hosted undergraduate student research experiences; for example, REACCH annually recruits undergraduates nationally into nine-week summer internships, and PINEMAP has instituted an undergraduate fellowship program stressing research experiences and experiential science education training (see figure 2).

Managing the Data. Standards for the storage, preservation, and accessibility of research data are rapidly changing, with greater expectations and requirements across all of the sciences and by all federal funding agencies (Kowalczyk and Shankar 2011). Each of our projects has created the data management capacity and protocols to address these requirements and to ensure our data will be compatible with existing and envisioned national data networks and repositories. The REACCH system is illustrative and consists of a data library, an analysis tools library, and a data management policy that delineates protocols for data formatting and metatagging. The system can accommodate biophysical and social science data and formats ranging from simple tables to geospatially explicit model output layers. The Sustainable Corn research and project management databases give the team capacity to undertake data synthesis, interpretation, and modeling across multiple primary and secondary data sets and provide a web-based report and team interaction structure for accountability and communication (Herzmann et al. 2014). PINEMAP has developed the Terrestrial Carbon Information System (TerraC), which includes tools to upload, store, manage, query, analyze, and download data characterizing terrestrial C dynamics from various sources, including soils, plants/biomass, atmosphere, water, and whole ecosystems.

Communicating with Stakeholders. Our CAPs are charged to improve adaptation to anticipated climate change and to mitigate greenhouse gas emissions from agriculture. This can only be achieved with substantive communication and partnerships with agricultural producers, foresters, and other stakeholders. Each of our projects builds on existing networks with producers and agricultural industry personnel including, for PINEMAP, the large number of forest coop- 


\section{Figure 2}

Photos of USDA Climate Coordinated Agricultural Project activities. (a) Pine Integrated Network: Education, Mitigation, and Adaptation Project (PINEMAP) graduate student mentor Elizabeth Wilson (left) and undergraduate fellow Madison Wigley (right) measure loblolly pine seedlings in a greenhouse experiment at Texas A\&M University. The PINEMAP Undergraduate Fellow program pairs undergraduate students with PINEMAP graduate student mentors for a summer research experience. The following fall, Undergraduate Fellows participate in a distance course on experiential science education, and plan and deliver hands-on science lessons for local middle school students. (b) Wheat samples being collected for analyses in foreground and an eddy-covariance flux tower in the background at a Pacific Northwest Regional Approaches to Climate Change field site (Cook Agronomy Farm) near Pullman, Washington. The long-term experiment is examining greenhouse gas emissions and crop performance under different tillage methods. PhD student, Jishu (Jackie) Chi at work. (c) Sustainable Corn advisory board member and Soil and Water Conservation Society executive director Jim Gulliford (left), USDA National Institute of Food and Agriculture program leader Mary Ann Rozum (center), and Sustainable Corn agronomist Rick Cruse from lowa State University (right) discuss soil sampling protocols at a project field day held at a Purdue University research farm. Photo credits: (a) Ayumi Hyodo, (b) Laurel Graves, and (c) Lois Wright Morton.

(a)

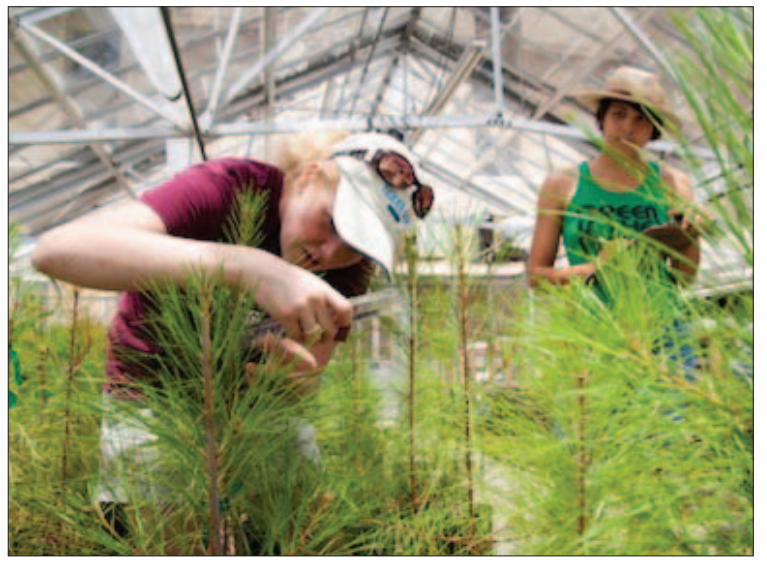

(b)

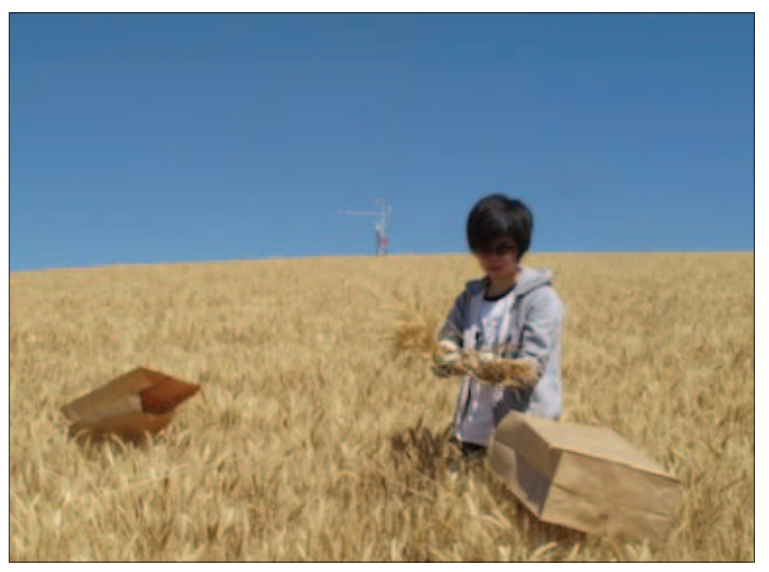

(c)

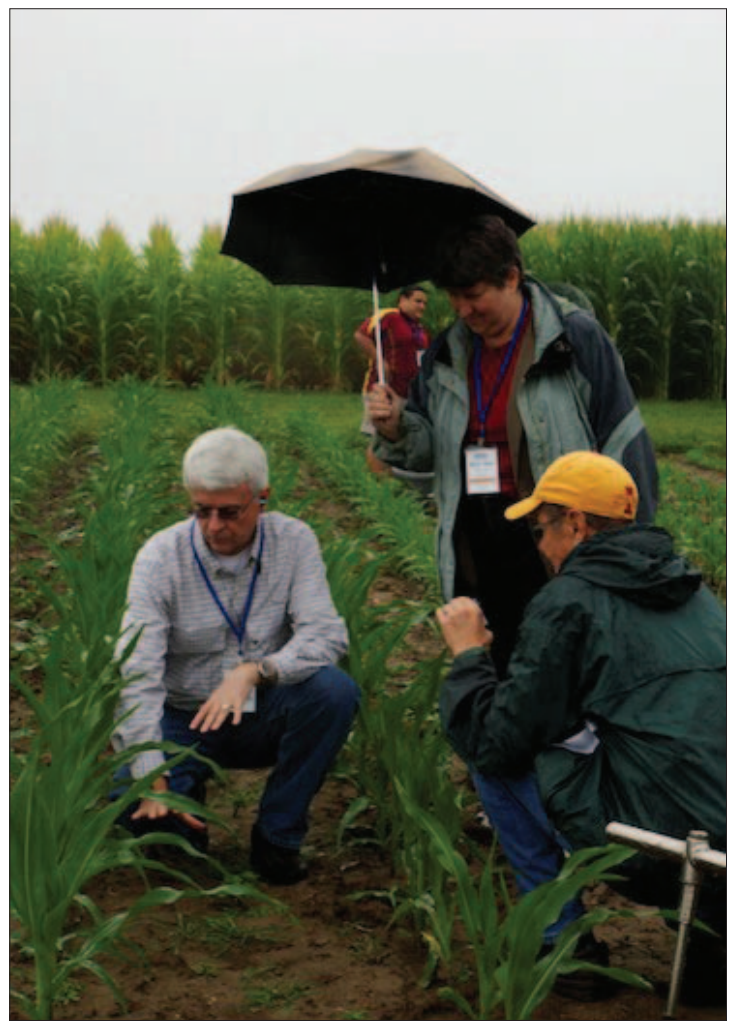

eratives in the region. The REACCH project has an extension lead PI and a fully funded, faculty-level position focused on extension and a mini-grant program to fund extensionrelated projects in the region competitively. Sustainable Corn has direct funding to 23 educators representing 10 land-grant university extension programs. All projects incorporate field days, published extension bulletins, web blogs, webinars, videos, and presentations to communicate project activities and information. Online and mobile decision support tools are in development or deployed as part of collaborations (https:// mygeohub.org/groups/u2u). Examples of our extension-related online activities can be found at www.agriclimateconnection. org; http://www.pinemap.org/extension; http://agclimate.net; and https://www.reacchpna.org/mission/extension/.

Working Together. The NIFA Climate CAP project directors (coauthors of this paper) have worked together actively and regularly since our projects were initiated in 2011, attending one another's annual meetings personally or via representatives and convening regular video conferences (about 10 per year) with the intent to learn from each other and contribute to improved understanding of large-scale projects. Our projects' managers also meet by phone conference monthly, and other personnel across our projects are collaborating.

\section{LOOKING TO THE FUTURE}

NIFA's Climate CAPs are part of the agency's new model that includes large-scale, outcome-focused efforts that pursue integrated, transdisciplinary research, teaching, and extension. The need for integration projects like the climate CAPs to address the long-term sustainability of agricultural and natural resource management systems has been articulated (Robertson et al. 2008), but determining how best to incorporate such projects into the long-term portfolio of agricultural and natural resources research is not yet clear. Investments of this kind will depend upon priority setting within NIFA and how their complementary roles are understood in 
conjunction with the Long Term Agricultural Project Network and the regional USDA Climate Hubs, as well as existing smallerscale, foundational science research. Each of our CAPs has unique resources, assets, and interdisciplinary relationships, which will be valuable to future platforms of research, extension, and education initiated by USDA. As project directors, we are committed to ensuring that all we are learning can contribute to the USDA's leadership in addressing complex issues facing sustainable agricultural production and natural resource management in a changing and increasingly competitive world.

\section{ACKNOWLEDGEMENTS}

These regional collaborative projects are funded by three USDA National Institute of Food and Agriculture Coordinated Agricultural Project awards: No. 201168002-30190, Cropping Systems Coordinated Agricultural Project: Climate Change, Mitigation, and Adaptation in Corn-based Cropping Systems to 11 institutions (Iowa State University, Lincoln University, Michigan State University, The Ohio State University, Purdue University, South Dakota State University, University of Illinois, University of Minnesota, University of Missouri, and University of Wisconsin), and USDA Agricultural Research Service (ARS), Columbus, Ohio; No. 201168002-30191, Pacific Northwest Regional Approaches to Climate Change to 3 institutions (University of Idaho, Oregon State University, and Washington State University) and USDA ARS, Pullman, Washington; and No. 2011-68002-30185, The Pine Integrated Network: Education, Mitigation, and Adaptation Project to 11 southeastern land-grant universities (University of Florida, Alcorn State University, Auburn University, University of Georgia, Mississippi State University, North Carolina A\&T University, North Carolina State University, Oklahoma State University Texas A\&M University, Virginia Polytechnic Institute and State University, and Virginia State University) and the USDA Forest Service.

\section{REFERENCES}

Andersen, H. 2013. The second essential tension: On tradition and innovation in interdisciplinary research. Topoi 32:3-8.

Association of Public and Land-grant Universities, Board on Natural Resources and Board on Oceans, Atmosphere, and Climate. 2014. Science, Education and Outreach Roadmap for Natural Resources. May 2014.

Basche, A.D., G.E. Roesch-McNally, L.A. Pease, C.D. Eidson, G.B. Lahdou, M.W. Dunbar, T.J. Frank, L Frescoln, L. Gu, R. Nagelkirk, J. Pantoja, and A.K. Wilke. Challenges and opportunities in transdisciplinary science: The experience of the next generation scientists in an agriculture and climate research collaboration. Journal of Soil and Water Conservation 69(6):176A-179A.

Cummings, J.N., and S. Kiesler. 2005. Collaborative research across disciplinary and organizational boundaries. Social Studies of Science 35(5):703-722

Cummings, J.N., and S. Kiesler. 2007. Coordination costs and project outcomes in multi-uni- versity collaborations. Research Policy 36(10):1620-1634

Dalton, M.M., P. Mote, and A.K. Snover, editors. 2013. Climate Change in the Northwest: Implication for our Landscapes, Waters, and Communities Washington, DC: Island Press.

Davison, R.B., J.R. Hollenbeck, C.M. Barnes, D.J Sleesman, and D.R. Ilgen. 2012. Coordinated action in multiteam systems. Journal of Applied Psychology 97:808-824.

Derrick, E.G., H.J. Falk-Krzesinski, M.R. Roberts, and S. Olson. 2012. Facilitating Interdisciplinary Research and Education: A Practical Guide. Washington, DC: American Association for the Advancement of Science.

Eigenbrode, S.D., M. O'Rourke, D.M. Althoff, C.S Goldberg, K. Merrill, W. Morse, M. Nielsen-Pincus, J. Stephens, L. Winowiecki, J.D. Wulfhorst, and N.A. Bosque-Pérez. 2007. Employing philosophical dialogue in collaborative science. Bioscience 57(1):55-64

Fortin, J.M., and D.J. Currie. 2013. Big science vs. little science: How scientific impact scales with funding. PLoS ONE 8(6):1-9 e65263.

Galison, P. 1994. Big Science:The Growth of Large Scale Research. Stanford, CA: Stanford University Press.

Haines,V.A.,J.Godley, and P.Hawe.2011.Understanding interdisciplinary collaborations as social networks. American Journal of Community Psychology 47(1-2):1-11.

Herzmann, D.E., L.J. Abendroth, and L.D Bunderson. 2014. Data management approach to multidisciplinary agricultural research and systheses. Journal of Soil and Water Conservation 69(6):180A-185A

Kadushin, C. 2012. Understanding Social Networks: Theories, Concepts, and Findings. Oxford: Oxford University Press.

Klein, J. 1996. Crossing Boundaries: Knowledge, Disciplinarities, and Interdisciplinarities. University Press of Virginia, Charlottesville.

Kowalczyk, S., and K. Shankar. 2011. Data sharing in the sciences. Annual Review of Information Science and Technology 45:247-294.

Kuhn,T.S. 1959. The essential tension:Tradition and innovation in scientific research. In Scientific Creativity: Its Recognition and Development, eds. C.W.Taylor and B. Frank, 341-354. New York:Wiley.

Looney, C., S. Donovan, M. O'Rourke, S. Crowley, S.D. Eigenbrode, L. Rotschy, N.A. Bosque-Pérez, and J.D. Wulfhorst. 2013. Seeing through the eyes of collaborators: Using toolbox workshops to enhance cross-disciplinary communication. In Enhancing Communication and Collaboration in Interdisciplinary Research, eds. M O'Rourke,S.Crowley,S.D.Eigenbrode, and J.D.Wulfhorst, 220-243.Thousand Oaks, CA: Sage Publications

Mathieu, J.E., M.A. Marks, and S.J. Zaccaro. 2001. Multiteam systems. In Handbook of Industrial, Work and Organizational Psychology: Vol. 2 Organizational Psychology, eds. N. Anderson, D. Ones, H. K. Sinangil, and C. Viswesvaran, 289313. Thousand Oaks, CA: Sage Publications.

Maznevski, M.L., and K.M. Chudoba. 2000. Bridging space over time: Global virtual team dynamics and effectiveness. Organization Science 11(5):473-492

Melillo, J.M., T.C. Richmond, and G.W.Yohe, eds. 2014. Highlights of Climate Change Impacts in the United States: The Third National Climate Assessment. Washington, DC: US Global Change Research Program, US Government Printing Office.

Monroe, M.C., J.T.T. Ireland, and T.A. Martin. 2014 Innovations in integrated graduate forestry education. Journal of Forestry. In press.
Morton, L.W., S.D. Eigenbrode, and T.A. Martin. The architecture of adaptive integration for transdisciplinary projects. Working paper.

National Academy of Sciences. 2004. Facilitating interdisciplinary research. Washington, DC: Committee on Facilitating Interdisciplinary Research and the Committee on Science Engineering and Public Policy, National Academies Press.

National Research Council. 2014. Convergence: Facilitating Transdisciplinary Integration of Life Sciences, Physical Sciences, Engineering, and Beyond. Washington, DC:The National Academies Press.

NIFA (National Institute of Food and Agriculture) 2010. Agriculture and Food Research Initiative Climate Change Request for Applications. Washington, DC: National Institute of Food and Agriculture. http://www.nifa.usda.gov/funding/ afri/pdfs/afri_climate_change_onepgr.pdf.

Palmer, M.A. 2012. Socioenvironmental sustainability and actionable science. Bioscience 62(1):5-6.

Pfirman, S., and P. Martin. 2010. Facilitating interdisciplinary scholars. In The Oxford Handbook of Interdisciplinarity, eds. R. Frodeman, J. T. Klein, and C. Mitcham, 387-403. Oxford, UK: Oxford University Press.

Robertson, G.P., V.G. Allen, G. Boody, E.R. Boose, N.G. Creamer, L.E. Drinkwater, J.R. Gosz, L. Lynch, J.L. Havlin, L.E. Jackson, S.T.A. Pickett, L. Pitelka, A. Randall, A.S. Reed, T.R. Seastedt, R.B. Waide, and D.H. Wall. 2008. Long-term agricultural research: A research, education, and extension imperative. Bioscience 58(7):640-645.

Tress, G., B. Tress, and G. Fry. 2007. Analysis of the barriers to integration in landscape research projects. Land Use Policy 24(2):374-385.

USDA. 2014. USDA Regional Climate Hubs. Washington, DC: USDA Office of the Chief Economist. http://www.usda.gov/oce/climate_ change/regional_hubs.htm.

USDA ARS (Agricultural Research Service). 2014 National Program 211: Water Availability and Water Management, Long-Term Agroecosystem Research (LTAR) Network. Washington, DC: USDA Agricultural Research Service. http:// www.ars.usda.gov/research/programs/programs. htm?np_code $=211 \&$ docid $=22480$.

Vasileiadou, E. 2012. Research teams as complex systems: Implications for knowledge management. Knowledge Management Research and Practice 10(2):118-127.

Walthall, C.L., J. Hatfield, P. Backlund, L. Lengnick, E. Marshall, M. Walsh, S. Adkins, M. Aillery, E.A. Ainsworth, C. Ammann, C.J. Anderson, I. Bartomeus, L.H. Baumgard, F. Booker, B. Bradley, D.M. Blumenthal, J. Bunce, K. Burkey, S.M Dabney,J.A.Delgado, J.Dukes,A. Funk, K. Garrett, M. Glenn, D.A. Grantz, D. Goodrich, S. Hu, R.C. Izaurralde, R.A.C.Jones, S.-H. Kim,A.D.B. Leaky, K. Lewers, T.L. Mader, A. McClung, J. Morgan, D.J. Muth, M. Nearing, D.M. Oosterhuis, D. Ort, C. Parmesan, W.T. Pettigrew, W. Polley, R. Rader, C. Rice, M. Rivington, E. Rosskopf, W.A Salas, L.E. Sollenberger, R. Srygley, C. Stöckle, E.S. Takle, D. Timlin, J.W. White, R. Winfree, L. Wright-Morton, and L.H. Ziska. 2012. Climate Change and Agriculture in the United States: Effects and Adaptation. USDA Technical Bulletin 1935. Washington, DC: USDA

Weinberg, A.M. 1961. Impact of large-scale science on the United States. Science 134(3473):161-164 